\title{
Thymol mitigates monosodium glutamate-induced neurotoxic cerebral and hippocampal injury in rats via overexpression of nuclear erythroid 2-related factor 2 signaling pathway as well as altering nuclear factor- kappa $\beta$ and glial fibrillary acidic protein expression
}

Rasha Mostafa ( $\sim$ dr_rosha81@yahoo.com )

National Research Centre https://orcid.org/0000-0002-5765-350X

Azza Hassan

CU Faculty of Veterinary Medicine: Cairo University Faculty of Veterinary Medicine

Abeer AA Salama

National Research Centre

Research Article

Keywords: Thymol, Monosodium glutamate, Neurotoxicity, Nrf2, NF-kß, GFAP

Posted Date: March 8th, 2021

DOl: https://doi.org/10.21203/rs.3.rs-170965/v1

License: (c) (i) This work is licensed under a Creative Commons Attribution 4.0 International License. Read Full License 


\section{Abstract}

Monosodium glutamate (MSG) is commonly used in various food industries as a flavor enhancer. MSG is reported to cause many toxic effects, including increased neurotoxicity. The study investigates the molecular mechanisms underlying thymol's neuroprotective effect against MSG-induced neurotoxic cerebral and hippocampal injury in rats. Brain injury was induced by MSG (2 g/kg; i.p.) for 15 days. Thymol (400 \& $800 \mathrm{mg} / \mathrm{kg} /$ day; p.o.) was administered along with MSG. MSG control rats showed a significant reduction in behavioral activity, elevated brain tissue oxidative stress, inflammatory parameters, Nrf2 gene up-regulation, overexpression of nuclear factor-kappa $\beta$ (NF-k $\beta$ ), glial fibrillary acidic protein (GFAP) as well as neuronal damage in the cerebral cortex \& hippocampus. Thymol ameliorated MSG-induced brain injury via overexpression of the Nrf2 gene, thus increasing the cellular defense and organizing antioxidant \& anti-inflammatory effects. Thymol improved behavioral activity and brain tissue GSH content. Thymol also decreased brain contents of MDA, NO, TNF-a \& IL-6. Moreover, Thymol improved NF-k $\beta$ \& GFAP immunohistochemical expression and histopathological picture in the cerebral cortex \& hippocampus compared to MSG control rats. The aforementioned results suggest that thymol exhibits promising neuroprotective effects. The study elucidates the molecular mechanisms linking Nrf2 pathway signaling to oxidative stress, inflammation \& NF-k $\beta$ expression underlying thymol's protection against MSG-induced neurotoxicity. The study also highlights the role of GFAP expression in MSG-induced astrocyte injury of cerebrum \& hippocampus of rats and the promising protective effects of thymol in ameliorating astrocyte injury.

\section{Introduction}

Monosodium glutamate (MSG), a salt form of L-glutamic acid, is commonly used in various food industries as a flavor enhancer (Ikeda 2002). MSG is abundant in high concentrations in commercially produced restaurant and household food products (Onaolapo et al. 2016). Despite its overspread use, MSG is always suspected to cause many toxic effects, collectively described as "The Chinese restaurant syndrome" (Walker and Lupien 2000). However, many countries pose no strict limitations on the permissible MSG concentrations in food. MSG is described to produce severe metabolic changes leading to a diverse arena of symptoms including flushing, sweating, weakness, dizziness, headache, and increased oxidative stress in the brain (Rotimi et al. 2012).

MSG dissociates in the body to yield sodium and glutamate ions (Quines et al. 2014). Ingested glutamate is metabolized in the gastrointestinal tract. As more glutamate is ingested, it gets absorbed via the portal vein (Reeds et al. 2000). Glutamate is the primary excitatory neurotransmitter in the human brain that plays a crucial role in brain development, synaptic plasticity, and learning (Maragakis and Rothstein 2001). Elevated glutamate concentrations produce abundant neurotoxicity via over-activation of excitatory amino acid receptors. This dilemma increases intracellular calcium, eventually resulting in cellular damage and severe brain excitotoxicity (Nagakannan et al. 2012). 
MSG administration damages the hypothalamic neurons and results in a modification in lipid peroxidation and oxidative stress in various areas of the brain, leading eventually to hyperexcitability and motor as well as behavioral changes (López-Pérez et al. 2010; Zanfirescu et al. 2019).

Therefore, MSG administration can be considered a reproducible neuro-toxic animal model, for testing drug's effects on oxidative stess and neurotoxic cerebral and hippocampal brain injury (Shivasharan et al. 2013).

Thyme (Thymus vulgaris L.; family Lamiaceae) is a plant native to Mediterranean countries with numerous medicinal and culinary properties (Zarzuelo and Crespo 2002). Thymol (2-isopropyl-5methylphenol) is the main constituent of thyme, contributing to about $10-64 \%$ of its essential oils (Fachini-Queiroz et al. 2012). Thyme is an antitussive, mucolytic, expectorant, sedative, antihypertensive, antimicrobial, antifungal, diuretic, antispasmodic, neuroprotective agent, and gastroprotective against ulcers (Salehi et al. 2018).

Moreover, many studies proved that thymol improves memory (Amiri 2012), possesses anti-cancer (Deb et al. 2011), anti-inflammatory (Liang et al. 2014) as well as immunomodulatory properties (Hashemipour et al. 2013). Most of these effects can be attributed to its antioxidant properties (Javed et al. 2019; Youdim and Deans 2000). However, the neuroprotective effects of thymol in neuro-toxic cerebral and hippocampal injury have not been well studied.

Therefore, the current study aims at testing the potential molecular mechanisms of the antioxidant and anti-inflammatory effects of thymol against MSG-induced neurotoxic cerebral and hippocampal injury in rats. The study outlines the possible involvement of nuclear erythroid 2-related factor 2 (Nrf2) signaling pathway as well as expression of tumor necrosis factor-alpha (TNF-a), interleukin-6 (IL-6), and nuclear factor-kappa $\beta$ (NF-k $\beta$ ) in brain tissues. The study also demonstrates the possible protective effects of thymol on the expression of glial fibrillary acidic proteins involved in neuronal damage of brain tissue.

\section{Materials And Methods}

\section{Animals}

Forty adult male Albino rats weighing 180-200 g were used in the current study. Standard food pellets and tap water were supplied ad libitum. Animals and food pellets were obtained from the animal house colony of the National Research Center (NRC, Egypt). The study was conducted in accordance with the National Research Centre-Medical Research Ethics Committee (NRC-MREC) for the use of animal subjects and following the recommendations of the National Institutes of Health Guide for Care and Use of Laboratory Animals (NIH Publications No. 8023, revised 2011).

\section{Drugs and chemicals}


MSG was purchased from Sigma (St. Louis, MO, USA). Thymol fluid extract (Thymotal ${ }^{\circledR}$ syrup; each $5 \mathrm{ml}$ contains 1.66 gram standardized to contain $0.03 \%$ phenolic compounds calculated as thymol; ATOS PHARMA, Egypt) was used throughout the study. All other chemicals were of the highest analytical grade available.

\section{Experimental design and treatment protocol}

Animals were randomly allocated into four groups (10 rats each). The 1st group's rats received intraperitoneal saline along with distilled water orally for 15 days and served as a normal control group. Brain injury was induced in the remaining 3 groups by intraperitoneal injection of monosodium glutamate ( $2 \mathrm{~g} / \mathrm{kg} /$ day) for 15 days. Group 2 received only distilled water orally for 15 days along with MSG and served as MSG control group. Groups $3 \& 4$ received thymol ( $400 \& 800 \mathrm{mg} / \mathrm{kg} /$ day; p.o.) respectively for 15 days. All animals were sacrificed $48 \mathrm{~h}$ after the last drug administration under sodium pentobarbital anesthesia.

\section{Methods}

\section{Behavioral tests}

\section{Spontaneous locomotor activity}

The locomotor activity was recorded by using an actophotometer (Ugo Basile, Milan, Italy). Actophotometer is a clear acrylic plastic box $(45 \times 45 \times 45 \mathrm{~cm})$ with a removable plastic lid perforated with ventilation holes. The device contains photocell beams and detectors that are mounted on opposite walls. Breaks of the photocell beams detect spontaneous locomotor activity. Before the locomotor task, animals were placed individually in the activity meter cage for 2 minutes for habituation. After that, locomotor activity was recorded as the counts within 5 minutes (Kulkarni 1987).

\section{Rotarod performance test}

Animals were trained to walk on the accelerating rotarod apparatus 2 days before recording the results (Ugo Basile 47600, Milan, Italy). The apparatus consists of a cylinder on which 5 animals can run simultaneously, separated by sufficient size panels to prevent the animals from detecting each other visually. The rod's speed was increased from $4 \mathrm{rpm}$ to $40 \mathrm{rpm}$ during $300 \mathrm{~s}$, then the animals were returned to their cages. When the animal could not maintain its balance and fell off the device, it triggered a sensor and the time was recorded (van den Berg et al. 2016).

\section{Tissue biochemical analysis}

Rats were sacrificed under sodium pentobarbital anesthesia, and their brains were carefully isolated and dissected through the midline into two hemispheres. $0.5 \mathrm{~g}$ of the affected hemisphere was homogenized (using MPW-120 homogenizer, Med instruments, Poland) to obtain 20\% homogenate; the homogenate was centrifuged using a cooling centrifuge (Laborezentrifugen, 2k15, Sigma, Germany) at 3000 r.p.m for 
10 min; the supernatant was taken for the determination of brain tissue concentrations of lipid peroxidation products ( malondialdehyde; MDA), nitric oxide (NO) metabolites and reduced glutathione (GSH) according to the methods adopted by Ruiz-Larrea et al. (1994) (Ruiz-Larrea et al. 1994), Miranda et al.(2001) (Miranda et al. 2001) and Ellman (1959) (Ellman 1959) \& modified by Bulaj et al. (1998) (Bulaj et al. 1998) respectively using commercially available kits (Biodiagnostic, Egypt). Brain tissue contents of TNF-a, as well as IL-6 were measured according to the method adopted by Brouckaert et al. (1993) (Brouckaert et al. 1993) using commercially available ELISA kits (SunRed, China).

\section{Real-time polymerase chain reaction (PCR) quantification of nuclear erythroid 2-related factor 2 (Nrf2)}

The mRNA expression level of the Nrf2 gene was assessed using real-time PCR standardized by coamplification with the housekeeping GAPDH gene as an internal control. Nrf2 RNA was extracted from brain tissue using Trizol reagent. RNA was reverse-transcribed using M-MLV reverse transcriptase (Invitrogen, Carlsbad, CA, USA) and then used for PCR with specific primers. Quantification of Nrf2 was carried out by using Nrf2 RT-PCR fluorescence diagnostic kit Cat. No. BSA05E3 according to manufactures' instructions (Stratagene, Agilent Biosciences, USA). For amplification, 1 cycle of 95区 c for 15 minutes and then 40 cycles of $94 \rrbracket$ c for 15 seconds, $55 \rrbracket$ c for 25 seconds, and $72 \rrbracket c$ for 25 seconds were performed with Nrf2 forward primer 5'-CAAAAGGAGCAAGAGAAAGCC-3', Nrf2 reverse primer 5'TCTGATTTGGGAATGTGGGC-3', GAPDH forward primer 5'-ACCACAGTCCATGCCATCAC-3' and GAPDH reverse 5'-TCCACCACCCTGTTGCTGTA-3' using Rotor-Gene Q5 plex real-time Rotary analyzer (Corbettlife sciences, USA) (Mostafa et al. 2016).

\section{Histopathological examination}

Following scarification, the brains were removed and fixed in $10 \%$ neutral formalin for $48 \mathrm{~h}$. Then, the brain tissues were coronally sectioned, washed, dehydrated in alcohol, and embedded in paraffin wax. The sections were cut into $4 \mu \mathrm{m}$ thickness and stained with H\&E for histopathological examination (Bancroft et al. 1996). For neuronal damage assessment, the number of degenerated and/or necrotic neurons was counted in five random high microscopic power fields (HPF) in both the cerebral cortex and hippocampus of normal and treated groups.

\section{Immunohistochemical analysis of nuclear factor-kappa $\beta$ expression (NF-k $\beta$ ) and glial fibrillary acidic protein (GFAP).}

All the immunohistochemical procedures for the demonstration of NF-k $\beta$ and GFAP expression were performed according to the method of Khalil et al. (2019) (Khalil et al. 2019). Briefly, the paraffinembedded brain sections were deparaffinized and rehydrated. Then, the sections were incubated with rabbit polyclonal anti- NF-k $\beta$ (ab16502) and anti-GFAP (ab7260) (Abcam) as primary antibodies. Finally, diaminobenzidine (DAB) (Sigma, USA) was used to visualize the immune reaction. Relying on the percentage of positive cells per HPF, the immune reactivity was semi-quantitatively assessed in ten random HPF, according to the method of Hassan et al. (2019), in which; $0=$ no staining, $1=$ positive staining 
in $<30 \%$ of cells per HPF, $2=$ positive staining in $30-70 \%$ of cells per HPF, or $3=$ positive staining in $>70 \%$ of cells per HPF (Hassan et al. 2019).

\section{Statistical analysis}

All the values are presented as means \pm standard error of the means (SEM). Comparisons between different groups were carried out using one-way analysis of variance (ANOVA) followed by Tukey's multiple comparison post hoc test. The difference was considered significant when $p \llbracket 0.05$. GraphPad prism ${ }^{\circledR}$ software (version 6 for Windows, San Diego, California, USA) was used to carry out these statistical tests.

\section{Results}

\section{Effects of thymol on spontaneous locomotor activity and rotarod rotation time in MSG-induced neurotoxic brain injury in rats.}

MSG (2 g/kg; i.p.) resulted in acute brain injury in rats, as evidenced by a significant reduction in animal's movement (measured as counts $/ 5 \mathrm{~min}$ ) to $52 \%$ compared to normal control animals.

The treatment of rats with thymol ( $400 \& 800 \mathrm{mg} / \mathrm{kg} /$ day; p.o) significantly improved the decreased spontaneous locomotor (measured as counts $/ 5 \mathrm{~min}$ ) to $152 \% \& 177 \%$ as respectively compared to the MSG control group.

MSG resulted in a significant reduction in animals' rotarod rotation time (seconds) to $28 \%$ compared to normal control animals.

While treatment of rats with thymol ( $400 \& 800 \mathrm{mg} / \mathrm{kg} /$ day; p.o) significantly improved the decreased rotarod rotation time (seconds) to $166 \% \& 226 \%$ respectively as compared to the MSG control group (Table 1). 
Table 1

Effects of thymol on spontaneous locomotor activity and rotarod rotation time in MSG-induced neurotoxic brain injury in rats.

\begin{tabular}{|c|c|c|}
\hline Groups & $\begin{array}{l}\text { Spontaneous locomotor activity } \\
\text { (counts/5 minutes) }\end{array}$ & $\begin{array}{l}\text { Rotarod rotation time } \\
\text { (seconds) }\end{array}$ \\
\hline Normal control & $133.40 \pm 7.49$ & $419.80 \pm 20.11$ \\
\hline $\begin{array}{l}\text { MSG control } \\
(2 \mathrm{~g} / \mathrm{kg} ; \text { i.p. })\end{array}$ & $68.83^{a} \pm 4.07$ & $117.00^{a} \pm 12.12$ \\
\hline $\begin{array}{l}\text { MSG + Thymol } \\
(400 \text { mg/kg/day; p.o.) }\end{array}$ & $97.40^{a, b} \pm 3.46$ & $194.00^{a, b} \pm 11.03$ \\
\hline $\begin{array}{l}\text { MSG + Thymol } \\
(800 \text { mg/kg/day; p.o.) }\end{array}$ & $122.00^{b} \pm 9.22$ & $265.00^{a, b} \pm 18.71$ \\
\hline \multicolumn{3}{|c|}{$\begin{array}{l}\text { Rats of the normal control group received intraperitoneal saline. Brain injury was induced in the } \\
\text { remaining } 3 \text { groups by intraperitoneal injection of monosodium glutamate }(2 \mathrm{~g} / \mathrm{kg} \text {; i.p.) for } 15 \text { days. } \\
\text { Group } 2 \text { received only distilled water orally along with MSG and served as MSG control group. Groups } \\
3 \& 4 \text { received thymol ( } 400 \& 800 \mathrm{mg} / \mathrm{kg} / \text { day; p.o.) respectively for } 15 \text { days. Spontaneous locomotor } \\
\text { activity and rotarod rotation time were recorded. }\end{array}$} \\
\hline \multicolumn{3}{|c|}{ Data is presented as mean \pm SEM $(n=10)$. } \\
\hline
\end{tabular}

Effects of thymol on brain tissue oxidative stress parameters in MSG-induced neurotoxic brain injury in rats.

MSG resulted in acute brain injury in rats as evidenced by the significant elevation of brain tissue concentration of MDA \& NO to $273 \%$ \& $201 \%$ respectively and the considerable reduction of GSH to $27 \%$ compared to the normal control group.

Treatment of rats with thymol ( $400 \& 800 \mathrm{mg} / \mathrm{kg} /$ day; p.o) significantly decreased the elevated brain tissue concentration of MDA to $79 \% \& 53 \%$, decreased the elevated brain tissue concentration of NO to $79 \% \& 63 \%$ and elevated brain tissue GSH concentration to $156 \% \& 233 \%$ respectively as compared to the MSG control group (Table 2). 
Table 2

Effects of thymol on brain tissue concentration of lipid peroxidation products (MDA), NO metabolites and GSH in MSG-induced neurotoxic brain injury in rats.

\begin{tabular}{|c|c|c|c|}
\hline Groups & $\begin{array}{l}\text { MDA } \\
\text { ( } \mu \mathrm{mol} / \mathrm{g} \text { wet tissue) }\end{array}$ & $\begin{array}{l}\text { NO } \\
\text { ( } \mu \mathrm{mol} / \mathrm{g} \text { wet tissue) }\end{array}$ & $\begin{array}{l}\text { GSH } \\
\text { ( } \mu \mathrm{mol} / \mathrm{g} \text { wet tissue) }\end{array}$ \\
\hline Normal control & $122.02 \pm 5.70$ & $56.34 \pm 3.78$ & $8.42 \pm 0.28$ \\
\hline $\begin{array}{l}\text { MSG control } \\
(2 \mathrm{~g} / \mathrm{kg} ; \text { i.p. })\end{array}$ & $333.74^{\mathrm{a}} \pm 13.78$ & $113.30^{\mathrm{a}} \pm 5.50$ & $2.27^{a} \pm 0.29$ \\
\hline $\begin{array}{l}\text { MSG + Thymol } \\
(400 \text { mg/kg/day; p.o.) }\end{array}$ & $262.44^{a, b} \pm 14.19$ & $89.34^{a, b} \pm 3.21$ & $3.54^{a, b} \pm 0.18$ \\
\hline $\begin{array}{l}\text { MSG + Thymol } \\
(800 \text { mg/kg/day; p.o.) }\end{array}$ & $178.24^{\mathrm{a}, \mathrm{b}} \pm 5.74$ & $71.22^{b} \pm 2.25$ & $5.28^{a, b} \pm 0.19$ \\
\hline \multicolumn{4}{|c|}{$\begin{array}{l}\text { Rats of the normal control group received intraperitoneal saline. Brain injury was induced in the } \\
\text { remaining } 3 \text { groups by intraperitoneal injection of monosodium glutamate }(2 \mathrm{~g} / \mathrm{kg} \text {; i.p.) for } 15 \text { days. } \\
\text { Group } 2 \text { received only distilled water orally along with MSG and served as MSG control group. Groups } \\
3 \& 4 \text { received thymol ( } 400 \& 800 \mathrm{mg} / \mathrm{kg} / \text { day; p.o.) respectively for } 15 \text { days. All animals were } \\
\text { sacrificed } 48 \mathrm{~h} \text { after the last drug administration, the brains were dissected out, homogenized and the } \\
\text { homogenate was obtained. }\end{array}$} \\
\hline \multicolumn{4}{|c|}{ Data is presented as mean $\pm \operatorname{SEM}(n=10)$. } \\
\hline $\begin{array}{l}\text { a Significantly differen } \\
\text { test). }{ }^{\text {b }} \text { Significantly dif }\end{array}$ & $\begin{array}{l}\text { e normal control } \mathrm{s} \\
\text { om MSG control g }\end{array}$ & $\begin{array}{l}t p<0.05 \text { (Tukey's } \\
p<0.05 \text { (Tukey's }\end{array}$ & $\begin{array}{l}c \\
\text { test). }\end{array}$ \\
\hline
\end{tabular}

Effects of thymol on brain tissue concentration of TNF- $a$ and IL-6 in MSG-induced neurotoxic brain injury in rats.

Acute brain injury in rats induced by MSG resulted in a significant elevation of brain tissue concentration of TNF-a \& IL-6 to $393 \%$ \& $432 \%$, respectively, as compared to the normal control group.

Treatment of rats with thymol ( $400 \& 800 \mathrm{mg} / \mathrm{kg} /$ day; p.o) significantly reduced the elevated brain tissue concentration of TNF-a to $68 \%$ \& $36 \%$, reduced the elevated brain tissue concentration of IL- 6 to $60 \%$ \& $38 \%$, respectively, as compared to the MSG control group (Fig. 1).

\section{Quantitative RT-PCR for Nrf2 gene expression in brain tissue}

The expression response of the Nrf2 gene in rat brains following monosodium glutamate-induced oxidative stress and neuro-toxic brain injury was analyzed using qRT-PCR. Nrf2 was up-regulated in the MSG-control group to reach 1.15 -fold as compared to the normal control group. 
Treatment of rats with thymol ( $400 \& 800 \mathrm{mg} / \mathrm{kg} /$ day; p.o) significantly overexpressed the Nrf2 gene in brain tissue to 1.32-fold\& 2.02-fold, respectively compared to the MSG control group (Fig. 2).

\section{Histopathological examination of cerebral cortex and hippocampus}

The result of the histopathological assessment of neuronal damage is illustrated in table 3 . Brains of normal rats showed typical histological structure with normal rounded cerebral cortical and hippocampal neurons (Figs. 3a \&3b, respectively). Meanwhile, apparent neuronal damage was demonstrated in the brains of MSG-treated rats. This damage was manifested by the presence of shrunken eosinophilic necrotic neurons associated with neuronophagia and diffuse proliferation of microglia cells and astrocytes that are characteristically demonstrated in the cerebral cortex (Fig. 3c) and hippocampus (Fig. 3d) of this group. Treatment with thymol remarkably ameliorates these histopathological alterations in a dose-dependent manner. A decreased number of degenerated and/or necrotic neurons and moderate gliosis were observed in the cerebral cortex and hippocampus of the MSG-Thymol (400 mg/kg) group (Fig. 3e \&3f, respectively). On the other side, minimal neuronal damage and gliosis were demonstrated in the MSG-Thymol ( $800 \mathrm{mg} / \mathrm{kg}$ ) group. Most of the cerebral cortical and hippocampal neurons appeared normal with scant degenerated ones (Fig. $3 g$ \& 3 , respectively).

Table 3

The number of degenerated and/or necrotic neurons recorded in the cerebral cortex and hippocampus of normal and treated rats.

\begin{tabular}{|lll|}
\hline \multirow{2}{*}{ Groups } & \multicolumn{2}{c|}{ Number of degenerated and/or necrotic neurons (NO/HPF) } \\
\cline { 2 - 3 } & Cerebral cortex & Hippocampus \\
\hline Normal control & $0.20^{\mathrm{a}} \pm 0.20$ & $0.40^{\mathrm{a}} \pm 0.24$ \\
\hline $\begin{array}{l}\text { MSG control } \\
(2 \mathrm{~g} / \mathrm{kg} \text {; i.p.) }\end{array}$ & $16.20^{\mathrm{b}} \pm 1.28$ & $11.80^{\mathrm{b}} \pm 1.06$ \\
\hline $\begin{array}{l}\text { MSG + Thymol } \\
(400 \mathrm{mg} / \mathrm{kg} / \text { day; p.o.) }\end{array}$ & $9.60^{\mathrm{c}} \pm 1.77$ & $5.00^{\mathrm{c}} \pm 0.83$ \\
\hline $\begin{array}{l}\text { MSG + Thymol } \\
(800 \mathrm{mg} / \mathrm{kg} / \text { day; p.o.) }\end{array}$ & $4.40^{\mathrm{d}} \pm 2.30$ & $3.40^{\mathrm{d}} \pm 0.60$ \\
\hline Different lowercase letters are significantly different $(\mathrm{p}<0.05)$. & \\
\hline
\end{tabular}

Immunohistochemical analysis of NF-k $\beta$ expression in cerebral cortex and hippocampus 
The results of immunohistochemical analysis of NF-k $\beta$ expression in the cerebral cortex and hippocampus are illustrated in table 4. Brains of normal rats showed normal cytoplasmic staining of neurons of both the cerebral cortex (Figure 4a) and hippocampus (Figure 4b) with no nuclear translocation evidence. On the contrary, the significant increase of NF-k $\beta$ expression was demonstrated mainly in the nuclei of cerebral cortical neurons (Figure 4c) and pyramidal cells of the hippocampus (Figure $4 \mathrm{~d}$ ). Conversely, the percentage of NF-k $\beta$-positively stained cells was significantly reduced in the cerebral cortex (Figure 4e) and hippocampus (Figure 4f) of the MSG-Thymol (400 mg/kg) group, in which most neurons showed cytoplasmic staining. Pronounced reduction of NF-k $\beta$ expression, with minimal nuclear staining, was demonstrated in the cerebral cortex (Figure 4g) and hippocampus (Figure 4h) of MSG-Thymol (800mg/kg) group.

Table 4

The results of NF-k $\beta$ expression recorded in the cerebral cortex and hippocampus of normal and treated rats

\begin{tabular}{|c|c|c|}
\hline \multirow[t]{2}{*}{ Groups } & \multicolumn{2}{|c|}{ NF-k $\beta$ expression (\%of positive cells/HPF) } \\
\hline & Cerebral cortex & Hippocampus \\
\hline Normal control & $0.10^{\mathrm{a}} \pm 0.10$ & $0.20^{\mathrm{a}} \pm 0.13$ \\
\hline $\begin{array}{l}\text { MSG control } \\
(2 \mathrm{~g} / \mathrm{kg} ; \text { i.p. })\end{array}$ & $2.70^{b} \pm 0.15$ & $2.30^{b} \pm 0.15$ \\
\hline $\begin{array}{l}\text { MSG + Thymol } \\
\text { (400 mg/kg/day; p.o.) }\end{array}$ & $2.10^{c} \pm 0.27$ & $1.20^{c} \pm 0.20$ \\
\hline $\begin{array}{l}\text { MSG + Thymol } \\
\text { (800 mg/kg/day; p.o.) }\end{array}$ & $1.30^{d} \pm 0.15$ & $1.10^{d} \pm 0.10$ \\
\hline
\end{tabular}


The results of immunohistochemical analysis of GFAP expression in the cerebral cortex and hippocampus are illustrated in table 5. Few weakly stained astrocytes with small cell bodies and short cytoplasmic processes were demonstrated in the cerebral cortex (Figure 5a) and hippocampus (Figure $5 b)$ of normal rats. Whereas the significant increase in the percentage of GFAP+ astrocytes with large hypertrophied cell bodies and thicker as well as longer cytoplasmic processes recorded in the cerebral cortex (Figure 5c) and hippocampus (Figure 5d) of MSG-treated rats. On the other hand, the percentage of GFAP+ astrocytes was significantly decreased in thyme-treated groups in a dose-dependent manner. Few GFAP+ astrocytes with hypertrophied cell bodies were demonstrated in the cerebral cortex of the MSGThymol (400mg/kg) group (Figure 5e). But these cells were much hypertrophied in the hippocampus of this group (Figure $5 f$ ). Significant reduction of GFAP+ astrocytes, which appeared in the focal aggregate, was demonstrated in the cerebral cortex and hippocampus of the MSG-Thymol $(800 \mathrm{mg} / \mathrm{kg}) \mathrm{group}$ (Figures $5 \mathrm{~g} \& 3 \mathrm{~h}$, respectively).

Table 5

The results of GFAP expression recorded in the cerebral cortex and hippocampus of normal and treated rats

\begin{tabular}{|lll|}
\hline \multirow{2}{*}{ Groups } & \multicolumn{2}{l|}{ GFAP expression (\%of positive cells/HPF) } \\
\cline { 2 - 3 } & Cerebral cortex & Hippocampus \\
\hline Normal control & $1.20^{\mathrm{a}} \pm 0.13$ & $1.10^{\mathrm{a}} \pm 0.10$ \\
\hline MSG control & $2.80^{\mathrm{b}} \pm 0.13$ & $2.90^{\mathrm{b}} \pm 0.10$ \\
$(2 \mathrm{~g} / \mathrm{kg} ; \mathrm{i.p.})$ & & \\
\hline MSG + Thymol & $1.90^{\mathrm{c}} \pm 0.17$ & $1.90^{\mathrm{c}} \pm 0.17$ \\
$(400 \mathrm{mg} / \mathrm{kg} /$ day; p.o.) & & $1.40^{\mathrm{a}} \pm 0.16$ \\
\hline MSG + Thymol & $1.60^{\mathrm{a}, \mathrm{c}} \pm 0.16$ \\
\hline$(800 \mathrm{mg} / \mathrm{kg} /$ day; p.o.) & \\
\hline Different lowercase letters are significantly different $(p<0.05)$. \\
\hline
\end{tabular}

\section{Discussion}

MSG is commonly used in various food industries as a flavor enhancer (Ikeda 2002). MSG is reported to produce severe metabolic changes leading to abundant neurotoxicity and motor as well as behavioral changes (Nagakannan et al. 2012). Therefore, the current study aims at scouting the potential underlying molecular mechanisms involved in MSG-induced neurotoxic brain injury in rats. This study is the first to evaluate the role of the Nrf2 signaling pathway as well as NF-k $\beta$ and GFAP expression in MSG-induced brain injury and the potential neuroprotective antioxidant and anti-inflammatory effects of thymol on MSG-induced neurotoxic cerebral and hippocampal injury in rats. 
In the current study, MSG administration resulted in a significant alteration in motor and behavioral activities in rats as manifested by a reduction of the spontaneous locomotor activity as well as the rotarod rotation time of rats. This data agrees with Shivasharan et al. (2013), who stated that MSG significantly decreased the locomotor activity of adult female Wistar rats (Shivasharan et al. 2013). Swamy et al. (2014) also demonstrated that MSG caused a significant reduction in spontaneous locomotor activity in Wistar albino rats (Swamy et al. 2013).

MSG administration also resulted in a significant elevation of lipid peroxidation products and NO metabolites with a substantial reduction in GSH concentration in rats' brain tissue compared to the normal group; indicating severe oxidative damage to brain tissues. Many studies agree with this data demonstrating alteration in brain tissues antioxidative defense mechanisms post-MSG administration (Onaolapo et al. 2016; Sadek et al. 2016; Shivasharan et al. 2013; Swamy et al. 2013).

In the current work, MSG administration resulted in a significant elevation of brain tissue concentration of IL-6 and TNF-a compared to the normal group; indicating significant inflammatory damage of brain tissue. Khalil and Khedr (2016) stated that MSG administration resulted in a significant inflammatory response to brain tissue as manifested by an elevation of TNF-a in the hippocampus of MSG-treated rats (Khalil and Khedr 2016).

In the current work, Nrf2 was up-regulated in the MSG-control group as compared to the normal control group. In the basal non-stressed condition, Nrf2 is primarily abundant in the cytoplasm bound to the cytoplasmic Kelch-like ECH associated protein 1(Keapl). Binding to Keap1 blocks Nrf2 activation to keep Nrf2 concentration low. In case of occurrence of any endogenous or exogenous cellular events mandating cellular defense mechanisms, abrupt induction of Nrf2 occurs. Oxidative stress and/or inflammation decouple Keap1 from Nrf2 to activate the latter along with a further synthesis of Nrf2. Nrf2 is then transferred into the nucleus to bind with antioxidant response elements (ARE); also known as electrophile response elements (EpRE). This binding further activates Nrf2/ARE pathway. Nrf2 activation eventually results in an organized antioxidant, anti-inflammatory and anti-apoptotic responses in vivo (Vomhof-DeKrey and Picklo Sr 2012). Nrf2 gene over-expression also stimulates protective proteins such as; the brain-derived neurotrophic factor, peroxisome proliferator-activated receptor gamma co-activator $1 \mathrm{a}$ and the auto-phagic protein p62. External causes can induce Nrf2 activation, and it has been linked to many endogenous pathophysiological defense mechanisms in numerous systems, including the cardiovascular and the nervous systems (Zhu et al. 2018). It has been confirmed that the Nrf2 pathway plays a crucial role in CNS, in the case of brain inflammation, acute cerebral injuries as well as neurodegenerative disorders (Sandberg et al. 2014). Besides, a significant increase of NF-k $\beta$ expression, in the current work, was demonstrated in the nuclei of cerebral cortical neurons and pyramidal cells of the hippocampus of the MSG-control group. NF-k $\beta$ is found to suppress the transcription of ARE-dependent genes, and thus it acts as a crucial regulator of inflammation. NF-k $\beta$ is inactivated in the cytoplasm via binding to an inhibitor of NF-k $\beta$-kinase subunit beta. The molecular mechanisms linking NF-k $\beta$ and Nrf2 are not yet well-defined. However, the Nrf2 gene contains binding sites for NF-k $\beta$ in the promoter region which proposes a possible inter-relation between these two inflammatory regulators (Nair et al. 2008). In 
line with our findings, many studies reported over-expression of Nrf2 as well as NF-k $\beta$ in different experimental animal models of brain injury. Li et al. (2016), Zhang et al. (2017) and Cheng et al. (2016) reported over-expression of Nrf2 signaling in experimental traumatic brain injury (Cheng et al. 2016; Li et al. 2016; Zhang et al. 2017). Wei et al. (2017) reported activation of the Nrf2 signaling pathway postintracerebral hemorrhage (Wei et al. 2017). Du et al. (2020) reported up-regulation of Keap1/Nrf2 pathway in MSG-induced obese cardiomyopathy (Du et al. 2020). Xu et al. (2020) reported overexpression of NF-k $\beta$ pathway in neuro-inflammation in rats following subarachnoid hemorrhage (Xu et al. 2020). In line with this data, Nurmasitoh et al. (2018) reported that NF-k $\beta$ reduction results in antioxidant and anti-inflammatory effects (Nurmasitoh et al. 2018). The current study showed a significant histopathological injury of the brains of MSG-treated rats as manifested by the presence of shrunken necrotic neurons and proliferation of microglia cells and astrocytes in the cerebral cortex and hippocampus. Many studies reported severe alteration in brain tissue histopathological picture following MSG administration. Shivasharan et al. (2013) reported the appearance of numerous shrunken cells in the hippocampus of MSG-treated rats (Shivasharan et al. 2013). Onaolapo et al. (2016) reported significant degenerative cerebrum changes of MSG-treated mice accompanied by loss of the cerebellar architecture, vacuolation, and loss of the Purkinje cell monolayer. They also reported distortion of normal hippocampal architecture, mild edema and abundance of degenerating pyramidal cells as well as distorted cellular morphology in the hippocampal region of MSG-treated mice (Onaolapo et al. 2016). Swamy et al. (2013) reported severe alterations in brains of MSG-treated rats as was apparent by cerebral edema, pyknosis, eosinophilia and karyorrhexis (Swamy et al. 2013). MSG was reported to cause severe histopathological alterations of the cerebrum, cerebellum and hippocampus of treated experimental animals (Zanfirescu et al. 2019).

Astrocytes makeup about $50 \%$ of the brain tissue and are essential for the normal physiology and survival of the neurons. GFAP is a crucial protein secreted by mature astrocytes. GFAP is an astrocytespecific marker that controls astrocytes' shape and movement. GFAP expression is an immunohistochemical marker for reactive astrocytes. GFAP is overexpressed in response to neuronal damage, especially synaptic efficacy (Hashem et al. 2012). The current study demonstrates a significant increase in the percentage of GFAP astrocytes with large hypertrophied cell bodies and thicker as well as longer cytoplasmic processes recorded in the cerebral cortex and hippocampus of MSG-treated rats. In line with this finding, Zaher (2020) reported significant histopathological alterations and severe GFAP immunoreactivity in the hippocampus of MSG-treated rats (Zaher 2020). Hashem et al. (2012) also described histological distortment accompanied by moderate GFAP immunohistochemical expression in the astrocytes of cytoplasm as well as a granular layer of the cerebellar cortex of MSG-treated rats (Hashem et al. 2012).

The current study aimed to test the protective effects of thymol against MSG-induced neuro-toxic cerebral and hippocampal injury in rats, emphasizing the potential molecular mechanisms underlying this neuroprotection. 
In the current work, thymol in the selected doses improved behavioral changes caused by MSG administration. This was manifested by an improvement of the decreased spontaneous locomotor and rotarod rotation time compared to the MSG control group.

Thymol has been reported to be a positive activator of the GABAA receptors in humans (Priestley et al. 2003). This may account for its neuroprotective effects, especially in the case of MSG-induced neurotoxicity. MSG dissociates in the body to yield glutamate ions producing abundant neuro-toxicity via over-activation of excitatory amino acid receptors. Sancheti et al. (2014) stated that thymol administration resulted in anti-epileptogenic activity in rats, manifested by improved locomotor activity and seizure score (Sancheti et al. 2014).

According to previous studies, thymol improved oxidative stress parameters by decreasing MDA and NO metabolites and increasing GSH concentration in brain tissues compared to the MSG control group. This can be attributed to thymol's antioxidative properties. Moreover, thymol administration resulted in a significant reduction of elevated IL- 6 and TNF-a concentration in brain tissues as compared to the MSGtreated group. This can be attributable to thymol's potential anti-inflammatory properties. The antiinflammatory effects of thymol also account for the significant reduction of NF-k $\beta$ immunohistochemical expression in the cerebral cortex and hippocampus of rats as compared to MSG-treated rats. Interestingly, thymol administration also resulted in considerable overexpression of the Nrf2 gene in brain tissue compared to the MSG control group. This indicates activation of the theNrf2 signaling pathway, which results in organized antioxidant, anti-inflammatory, anti-apoptotic actions. Thymol also improved the overall histopathological pictures of the cerebral cortex and hippocampus of rats. Moreover, thymol significantly decreased GFAP expression in the cerebral cortex and hippocampus compared to the MSG group.

In accordance with our results, Javed et al. (2019) stated that thymol administration resulted in significant attenuation of oxidative stress, inflammation, and neuronal damage induced by Parkinson's disease in rats. These actions were attributed to inhibition of lipid peroxidation, besides the restoration of $\mathrm{GSH}$, catalase and superoxide dismutase antioxidant activates. Thymol administration significantly decreased the pro-inflammatory cytokines, viz. IL-6, IL-1 $\beta$, and TNF- $\alpha$ and inhibited glial cell activation (Javed et al. 2019). In another study, thymol administration was associated with improved cognitive deficits due to up-regulation of the Nrf2 signaling pathway in mice (Li et al. 2017). Chamanara et al. (2019) reported significant NF-k $\beta$ signaling inhibition in acetic acid-induced inflammation in colon tissue in rats (Chamanara et al. 2019).

Further investigation is warranted to explore other potential pharmacological interventions to overcome MSG-induced neuro-toxic cerebral and hippocampal injury.

\section{Conclusion}

To summarize, from the current study, it can be concluded that thymol exhibited promising protective effects against MSG-induced neurotoxic cerebral and hippocampal injury in rats. These effects are 
mainly attributable to thymol's antioxidant and anti-inflammatory properties. These properties might be attributable to the up-regulation of the Nrf2 signaling pathway. The study elucidates the molecular mechanisms linking oxidative stress, inflammation, NF-kß expression and Nrf2 pathway signaling underlying thymol's protection against MSG-induced neurotoxicity. The study also highlights GFAP expression's role in MSG-induced astrocyte injury of the cerebral cortex \& hippocampus of rats and the promising protective effects of thymol in ameliorating astrocyte injury via reduction of elevated GFAP expression.

\section{Declarations}

Funding: The authors have no relevant financial or non-financial interests to disclose.

Conflicts of interest/Competing interests: The authors have no conflicts of interest to declare that are relevant to the content of this article.

Availability of data and material: All data will be available upon request

Code availability: Not applicable

Consent to participate: Not applicable

Consent for publication: Not applicable

Authors' contributions: All authors contributed to the study conception and design. Material preparation, data collection and analysis were performed by Rasha E. Mostafa and Abeer AA Salama. All histopathological and immunohistochemical experiments were conducted by Azza Hassan. The first draft of the manuscript was written by Rasha E. Mostafa and all authors commented on previous versions of the manuscript. All authors read and approved the final manuscript.

Ethics approval: The study was conducted in accordance with the National Research Centre-Medical Research Ethics Committee (NRC-MREC) for the use of animal subjects and following the recommendations of the National Institutes of Health Guide for Care and Use of Laboratory Animals (NIH Publications No. 8023, revised 2011).

\section{Abbreviations}

Monosodium glutamate (MSG); Nuclear erythroid 2-related factor 2 (Nrf2); Tumor necrosis factor-alpha (TNF-a); Interleukin-6 (IL-6); Nuclear factor-kappa $\beta$ (NF-k $\beta$ ); Glial fibrillary acidic proteins (GFAP); Malondialdehyde (MDA); Nitric oxide (NO); Reduced glutathione (GSH).

\section{References}


Amiri H (2012) Essential Oils Composition and Anti-oxidant Properties of Three <i>Thymus</i> Species Evidence-Based Complementary and Alternative Medicine 2012:728065 doi:10.1155/2012/728065

Bancroft J, Stevens A, Turner D (1996) Theory and practice of histological techniques 4th Ed Churchill Living Stone, New York Edinburgh Madrid, Sanfrancisco:20

Brouckaert P, Libert C, Everaerdt B, Takahashi N, Cauwels A, Fiers W (1993) Tumor necrosis factor, its receptors and the connection with interleukin 1 and interleukin 6 Immunobiology 187:317-329 doi:10.1016/s0171-2985(11)80347-5

Bulaj G, Kortemme T, Goldenberg DP (1998) Ionization-reactivity relationships for cysteine thiols in polypeptides Biochemistry 37:8965-8972 doi:10.1021/bi973101r

Chamanara M, Abdollahi A, Rezayat SM, Ghazi-Khansari M, Dehpour A, Nassireslami E, Rashidian A (2019) Thymol reduces acetic acid-induced inflammatory response through inhibition of NF-kB signaling pathway in rat colon tissue Inflammopharmacology 27:1275-1283

Cheng T et al. (2016) Cerebroprotection of flavanol (-)-epicatechin after traumatic brain injury via Nrf2dependent and-independent pathways Free Radical Biology and Medicine 92:15-28

Deb DD, Parimala G, Devi SS, Chakraborty T (2011) Effect of thymol on peripheral blood mononuclear cell PBMC and acute promyelotic cancer cell line HL-60 Chemico-biological interactions 193:97-106

Du J et al. (2020) Pentamethylquercetin Attenuates Cardiac Remodeling via Activation of the Sestrins/Keap1/Nrf2 Pathway in MSG-Induced Obese Mice BioMed research international 2020

Ellman GL (1959) Tissue sulfhydryl groups Archives of Biochemistry and Biophysics 82:70-77 doi:http://dx.doi.org/10.1016/0003-9861(59)90090-6

Fachini-Queiroz FC et al. (2012) Effects of thymol and carvacrol, constituents of Thymus vulgaris L. essential oil, on the inflammatory response Evidence-Based Complementary and Alternative Medicine 2012

Hashem HE, Safwat ME-D, Algaidi S (2012) The effect of monosodium glutamate on the cerebellar cortex of male albino rats and the protective role of vitamin C (histological and immunohistochemical study) Journal of molecular histology 43:179-186

Hashemipour H, Kermanshahi H, Golian A, Veldkamp T (2013) Effect of thymol and carvacrol feed supplementation on performance, antioxidant enzyme activities, fatty acid composition, digestive enzyme activities, and immune response in broiler chickens Poultry science 92:2059-2069

Hassan NF, Nada SA, Hassan A, El-Ansary MR, Al-Shorbagy MY, Abdelsalam RM (2019) Saroglitazar Deactivates the Hepatic LPS/TLR4 Signaling Pathway and Ameliorates Adipocyte Dysfunction in Rats with High-Fat Emulsion/LPS Model-Induced Non-alcoholic Steatohepatitis Inflammation 42:1056-1070 
Ikeda K (2002) New seasonings Chemical senses 27:847-849

Javed H, Azimullah S, Meeran M, Ansari SA, Ojha S (2019) Neuroprotective Effects of Thymol, a Dietary Monoterpene Against Dopaminergic Neurodegeneration in Rotenone-Induced Rat Model of Parkinson's Disease International journal of molecular sciences 20:1538

Khalil MN, Choucry MA, El AS, Hassan A, El-Marasy SA, El SA, Omar FA (2019) Ambrosin, a potent NF-к $\beta$ inhibitor, ameliorates lipopolysaccharide induced memory impairment, comparison to curcumin PloS one 14:e0219378-e0219378

Khalil RM, Khedr NF (2016) Curcumin Protects against Monosodium Glutamate Neurotoxicity and Decreasing NMDA2B and mGluR5 Expression in Rat Hippocampus Neurosignals 24:81-87 doi:10.1159/000442614

Kulkarni S (1987) Experiments on isolated preparation Hand book of experimental pharmacology 3 Li H, Qin T, Li M, Ma S (2017) Thymol improves high-fat diet-induced cognitive deficits in mice via ameliorating brain insulin resistance and up-regulating NRF2/HO-1 pathway Metabolic brain disease 32:385-393

Li X et al. (2016) Protective effects of quercetin on mitochondrial biogenesis in experimental traumatic brain injury via the Nrf2 signaling pathway PLoS One 11

Liang D et al. (2014) Thymol inhibits LPS-stimulated inflammatory response via down-regulation of NFKB and MAPK signaling pathways in mouse mammary epithelial cells Inflammation 37:214-222

López-Pérez SJ, Ureña-Guerrero ME, Morales-Villagrán A (2010) Monosodium glutamate neonatal treatment as a seizure and excitotoxic model Brain research 1317:246-256

Maragakis NJ, Rothstein JD (2001) Glutamate transporters in neurologic disease Archives of neurology 58:365-370

Miranda KM, Espey MG, Wink DA (2001) A Rapid, Simple Spectrophotometric Method for Simultaneous Detection of Nitrate and Nitrite Nitric Oxide 5:62-71 doi:http://dx.doi.org/10.1006/niox.2000.0319

Mostafa RE, Salama AA, Abdel-Rahman RF, Ogaly HA (2016) Hepato-and neuro-protective influences of biopropolis on thioacetamide-induced acute hepatic encephalopathy in rats Canadian Journal of Physiology and Pharmacology 95:539-547

Nagakannan P, Shivasharan B, Thippeswamy B, Veerapur V, Bansal P (2012) Protective effect of hydroalcoholic extract of Mimusops elengi Linn. flowers against middle cerebral artery occlusion induced brain injury in rats Journal of ethnopharmacology 140:247-254 
Nair S, Doh S, Chan J, Kong A-N, Cai L (2008) Regulatory potential for concerted modulation of Nrf2-and Nfkb1-mediated gene expression in inflammation and carcinogenesis British journal of cancer 99:20702082

Nurmasitoh T, Sari DCR, Partadiredja G (2018) The effects of black garlic on the working memory and pyramidal cell number of medial prefrontal cortex of rats exposed to monosodium glutamate Drug and chemical toxicology 41:324-329

Onaolapo OJ, Onaolapo AY, Akanmu M, Gbola O (2016) Evidence of alterations in brain structure and antioxidant status following 'low-dose'monosodium glutamate ingestion Pathophysiology 23:147-156

Priestley CM, Williamson EM, Wafford KA, Sattelle DB (2003) Thymol, a constituent of thyme essential oil, is a positive allosteric modulator of human GABAA receptors and a homo-oligomeric GABA receptor from Drosophila melanogaster British journal of pharmacology 140:1363-1372

Quines CB, Rosa SG, Da Rocha JT, Gai BM, Bortolatto CF, Duarte MMM, Nogueira CW (2014) Monosodium glutamate, a food additive, induces depressive-like and anxiogenic-like behaviors in young rats Life sciences 107:27-31

Reeds PJ, Burrin DG, Stoll B, Jahoor F (2000) Intestinal glutamate metabolism The Journal of nutrition 130:978S-982S

Rotimi OA, Olayiwola I, Ademuyiwa O, Balogun EA (2012) Effects of fibre-enriched diets on tissue lipid profiles of MSG obese rats Food and chemical toxicology 50:4062-4067

Ruiz-Larrea MB, Leal AM, Liza M, Lacort M, de Groot H (1994) Antioxidant effects of estradiol and 2hydroxyestradiol on iron-induced lipid peroxidation of rat liver microsomes Steroids 59:383-388

Sadek K, Abouzed T, Nasr S (2016) Lycopene modulates cholinergic dysfunction, Bcl-2/Bax balance, and antioxidant enzymes gene transcripts in monosodium glutamate (E621) induced neurotoxicity in a rat model Canadian journal of physiology and pharmacology 94:394-401

Salehi B et al. (2018) Thymol, thyme, and other plant sources: Health and potential uses Phytotherapy Research 32:1688-1706

Sancheti J, Shaikh MF, Chaudhari R, Somani G, Patil S, Jain P, Sathaye S (2014) Characterization of anticonvulsant and antiepileptogenic potential of thymol in various experimental models NaunynSchmiedeberg's archives of pharmacology 387:59-66

Sandberg M, Patil J, D'Angelo B, Weber SG, Mallard C (2014) NRF2-regulation in brain health and disease: implication of cerebral inflammation Neuropharmacology 79:298-306

Shivasharan B, Nagakannan P, Thippeswamy B, Veerapur V (2013) Protective effect of Calendula officinalis $L$. flowers against monosodium glutamate induced oxidative stress and excitotoxic brain 
damage in rats Indian Journal of Clinical Biochemistry 28:292-298

Swamy AV, Patel N, Gadad P, Koti B, Patel U, Thippeswamy A, Manjula D (2013) Neuroprotective activity of pongamia pinnata in monosodium glutamate-induced neurotoxicity in rats Indian journal of pharmaceutical sciences 75:657

van den Berg R, Laman JD, van Meurs M, Hintzen RQ, Hoogenraad CC (2016) Rotarod motor performance and advanced spinal cord lesion image analysis refine assessment of neurodegeneration in experimental autoimmune encephalomyelitis Journal of neuroscience methods 262:66-76

Vomhof-DeKrey EE, Picklo Sr MJ (2012) The Nrf2-antioxidant response element pathway: a target for regulating energy metabolism The Journal of nutritional biochemistry 23:1201-1206

Walker R, Lupien JR (2000) The safety evaluation of monosodium glutamate The Journal of nutrition 130:1049S-1052S

Wei C-C, Kong Y-Y, Li G-Q, Guan Y-F, Wang P, Miao C-Y (2017) Nicotinamide mononucleotide attenuates brain injury after intracerebral hemorrhage by activating Nrf2/HO-1 signaling pathway Scientific reports 7:1-13

Xu W et al. (2020) Activation of Melanocortin 1 Receptor Attenuates Early Brain Injury in a Rat Model of Subarachnoid Hemorrhage viathe Suppression of Neuroinflammation through AMPK/TBK1/NF-KB Pathway in Rats Neurotherapeutics 17:294-308

Youdim KA, Deans SG (2000) Effect of thyme oil and thymol dietary supplementation on the antioxidant status and fatty acid composition of the ageing rat brain British Journal of Nutrition 83:87-93

Zaher EA (2020) The possible neuroprotective effect of astaxanthin on monosodium glutamate and aspartame induced hippocampal changes in albino rats:(Histological and immuno-histochemical study) Egyptian Journal of Histology

Zanfirescu A et al. (2019) A Review of the Alleged Health Hazards of Monosodium Glutamate Comprehensive Reviews in Food Science and Food Safety

Zarzuelo A, Crespo E (2002) The medicinal and non-medicinal uses of thyme Thyme: The Genus Thymus $17: 263-292$

Zhang $L$ et al. (2017) Fucoxanthin provides neuroprotection in models of traumatic brain injury via the Nrf2-ARE and Nrf2-autophagy pathways Scientific reports 7:46763

Zhu W, Ding Y, Kong W, Li T, Chen H (2018) Docosahexaenoic acid (DHA) provides neuroprotection in traumatic brain injury models via activating Nrf2-ARE signaling Inflammation 41:1182-1193

\section{Figures}


(a)

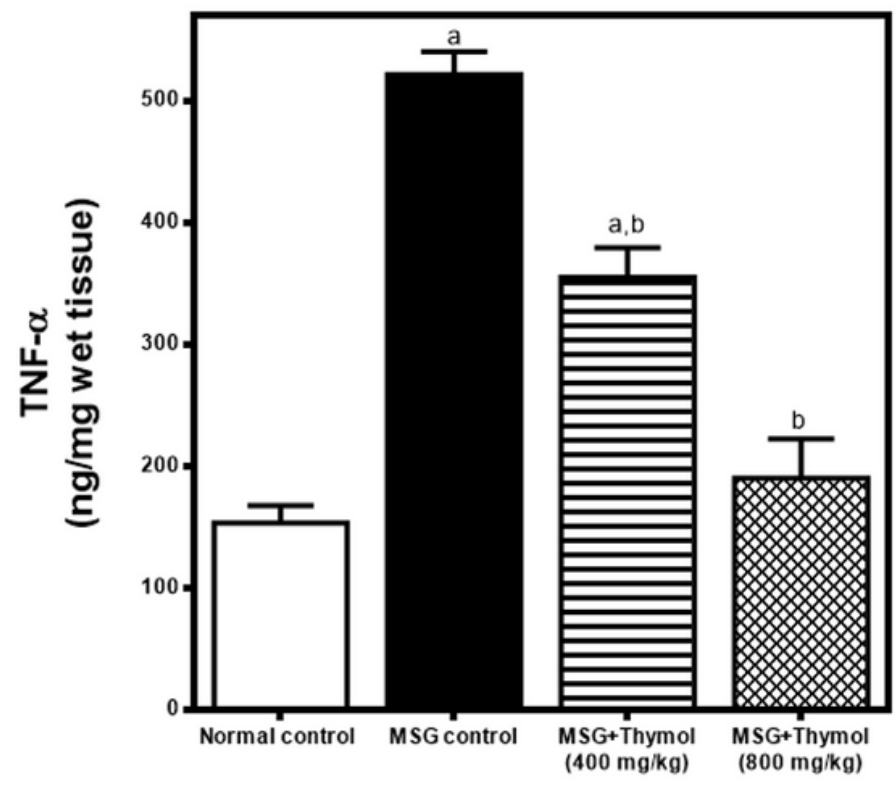

(b)

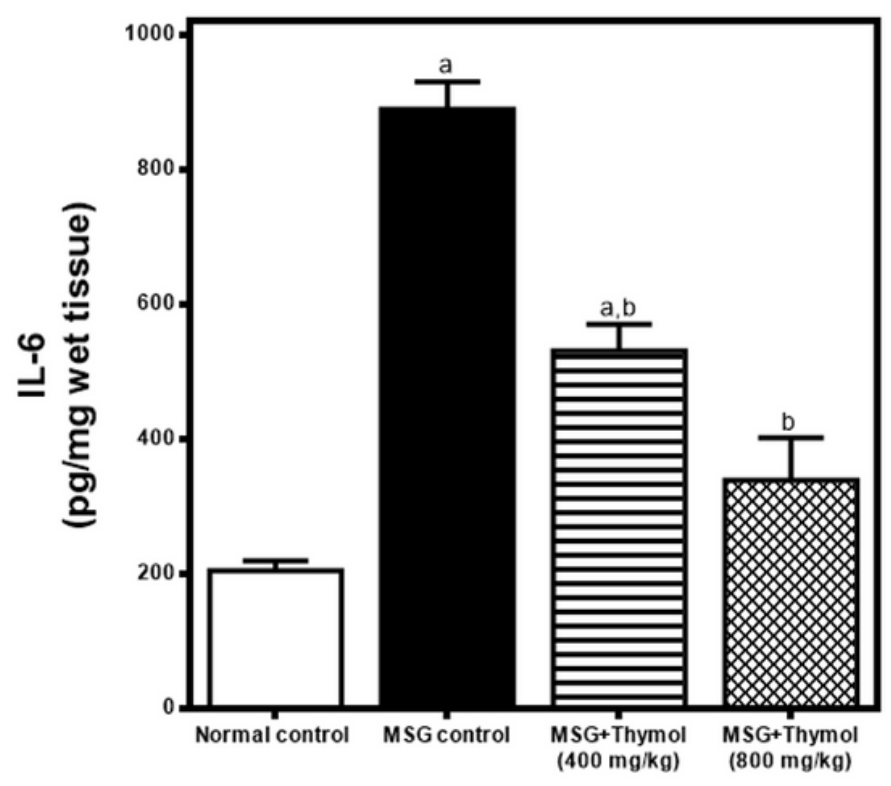

Figure 1

Effects of thymol on brain tissue concentration of (a) TNF- $a$ and (b) IL-6 in monosodium glutamateinduced neurotoxic brain injury in rats. Rats of the normal control group received intraperitoneal saline. Brain injury was induced in the remaining 3 groups by intraperitoneal injection of monosodium glutamate ( $2 \mathrm{~g} / \mathrm{kg}$; i.p.) for 15 days. Group 2 received only distilled water orally along with MSG and served as MSG control group. Groups $3 \& 4$ received thymol ( $400 \& 800 \mathrm{mg} / \mathrm{kg} /$ day; p.o.) respectively for 15 days. All animals were sacrificed $48 \mathrm{~h}$ after the last drug administration, the brains were dissected out, homogenized and the homogenate was obtained. Data is presented as mean \pm SEM $(n=10)$. a Significantly different from the normal control group at $p<0.05$ (Tukey's post hoc test). b Significantly different from MSG control group at $p<0.05$ (Tukey's post hoc test). 


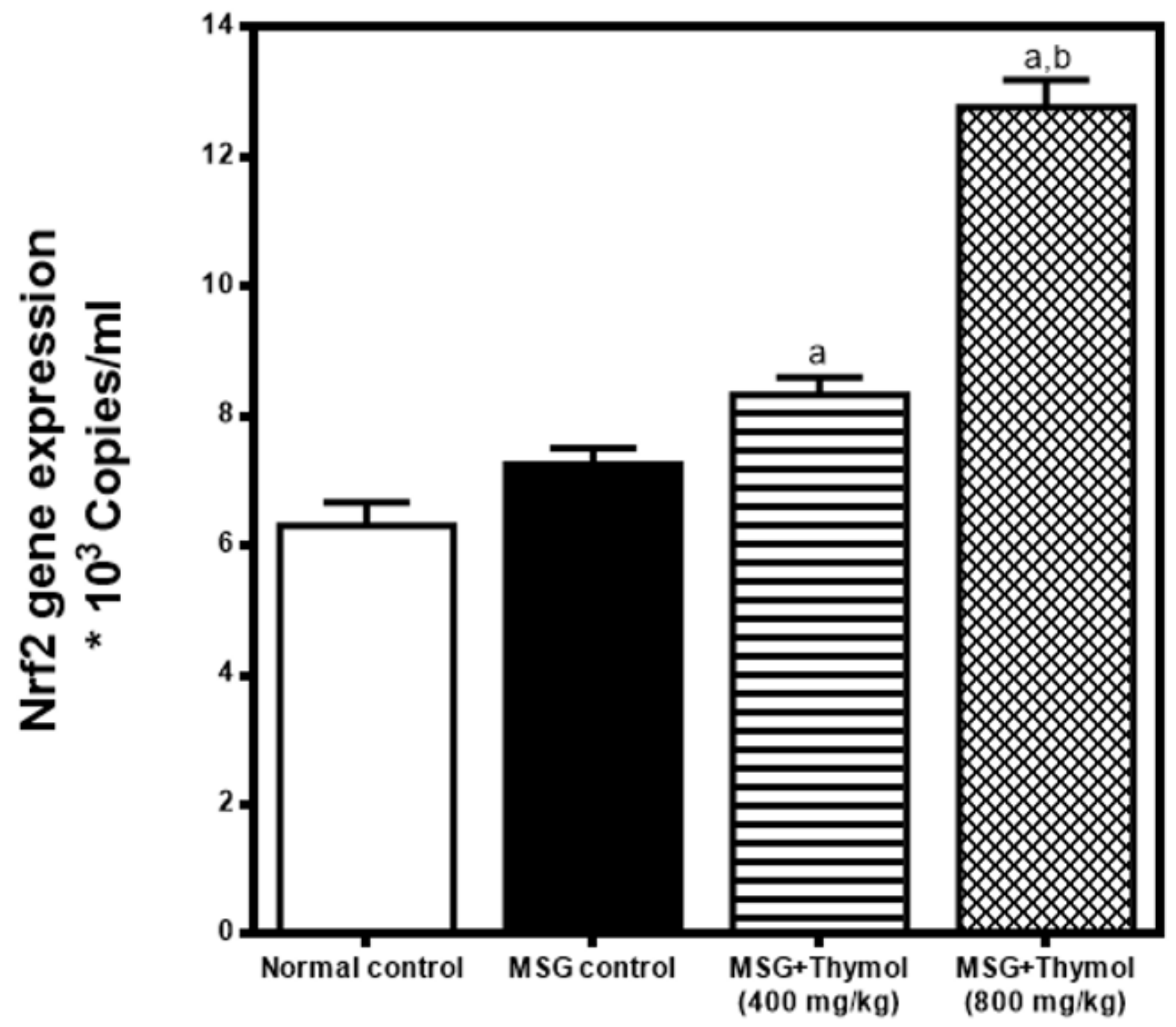

Figure 2

Real-time PCR quantitation of mRNA expression level of Nrf2 gene in brain tissue in MSG-induced neurotoxic brain injury in rats. Rats of the normal control group received intraperitoneal saline. Brain injury was induced in the remaining 3 groups by intraperitoneal injection of monosodium glutamate (2 $\mathrm{g} / \mathrm{kg}$; i.p.) for 15 days. Group 2 received only distilled water orally along with MSG and served as MSG control group. Groups $3 \& 4$ received thymol ( $400 \& 800 \mathrm{mg} / \mathrm{kg} /$ day; p.o.) respectively for 15 days. All animals were sacrificed $48 \mathrm{~h}$ after the last drug administration, the brains were dissected out, homogenized and the homogenate was obtained. Data is presented as mean \pm SEM $(n=10)$. a Significantly different from the normal control group at $p<0.05$ (Tukey's post hoc test). b Significantly different from MSG control group at $p<0.05$ (Tukey's post hoc test). 


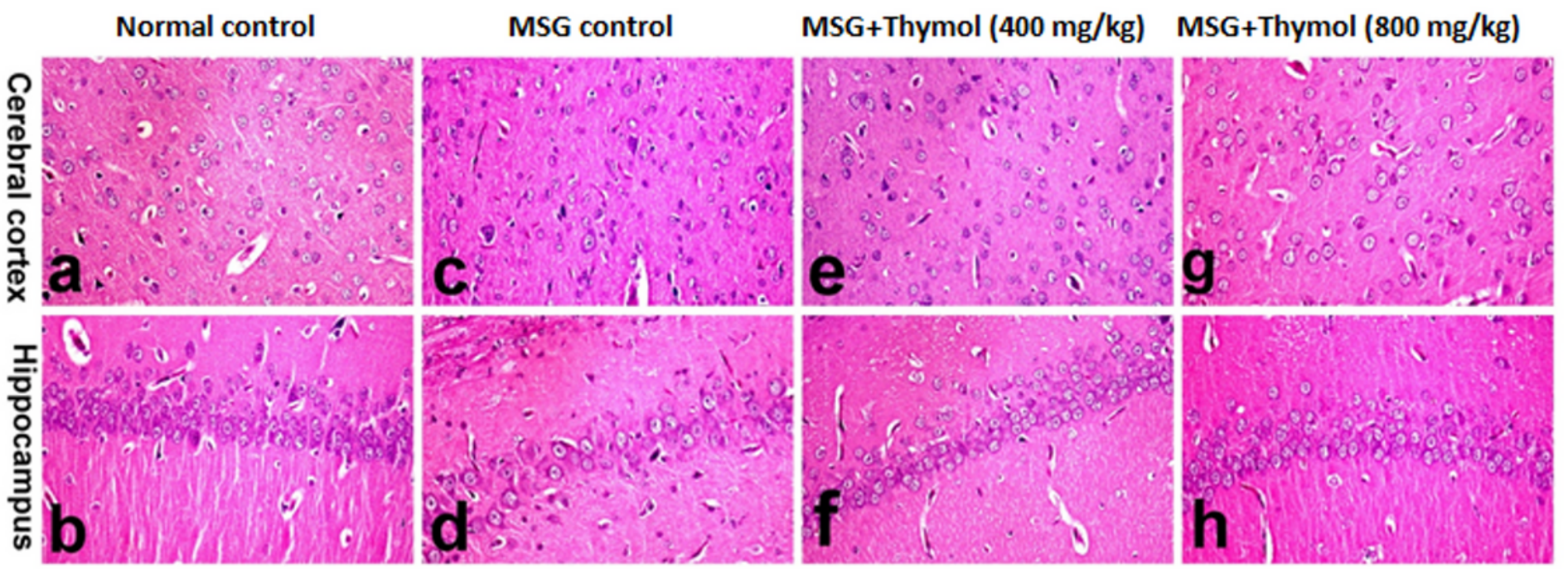

Figure 3

Histopathological examination of cerebral cortex and hippocampus Brain tissues, stained with H\&E, of (a, b) normal rats showing normal rounded neurons of the cerebral cortex (a) and hippocampus (b); (c,d) MSG-treated rats showing shrunken eosinophilic necrotic neurons (short arrow) associated with neuronophagia (long arrow) (and diffuse proliferation astrocytes (dashed arrow) in the cerebral cortex (c) and hippocampus (d); (e,f) MSG-Thymol (400mg/kg b.w.)-treated rats showing decreased number of degenerated and/or necrotic neurons in the cerebral cortex (e) and hippocampus (f); (g,h) MSG-Thymol $(800 \mathrm{mg} / \mathrm{kg}$ b.w.)-treated rats showing scant degenerated neurons in the cerebral cortex $(\mathrm{g})$ and normal hippocampus (h). (Stain: H\&E, 40X).

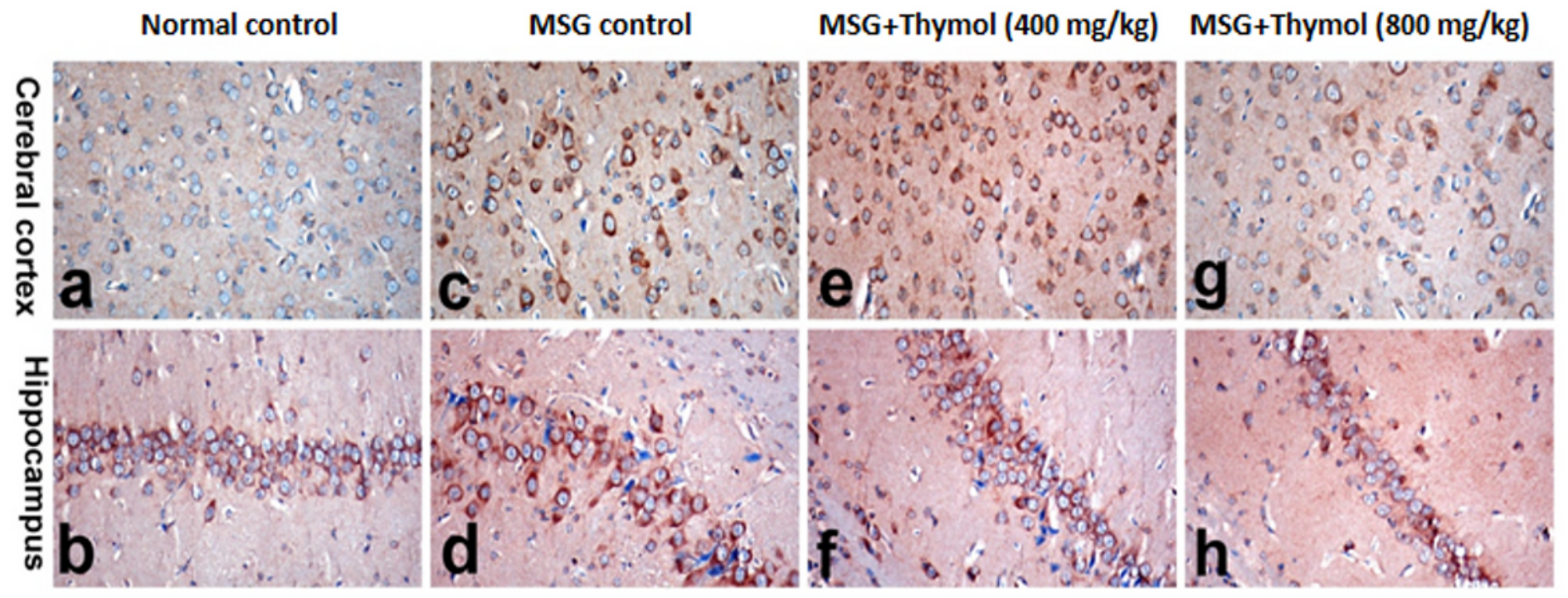

\section{Figure 4}

Immunohistochemical analysis of NF-k $\beta$ expression in cerebral cortex and hippocampus Brain tissues, immunohistochemically stained with NF-k $\beta$, of $(a, b)$ normal rats showing normal cytoplasmic staining of 
neurons of both cerebral cortex (a) and hippocampus (b); (c,d) MSG-treated rats showing a significant increase of NF-k $\beta$ expression in the nuclei of cerebral cortical neurons (c) and pyramidal cells of the hippocampus(d); (e,f) MSG-Thymol (400mg/kg)-treated rats showing a decreased percentage of NF-k $\beta$ positively stained cells with nuclear staining in the cerebral cortex (e) and hippocampus (f); (g,h) MSGThymol $(800 \mathrm{mg} / \mathrm{kg})$-treated rats showing pronounced reduction of NF-k $\beta$ expression, with minimal nuclear staining in the cerebral cortex (g) and hippocampus (h). (NF-k $\beta$ immunohistochemical staining, 40X).

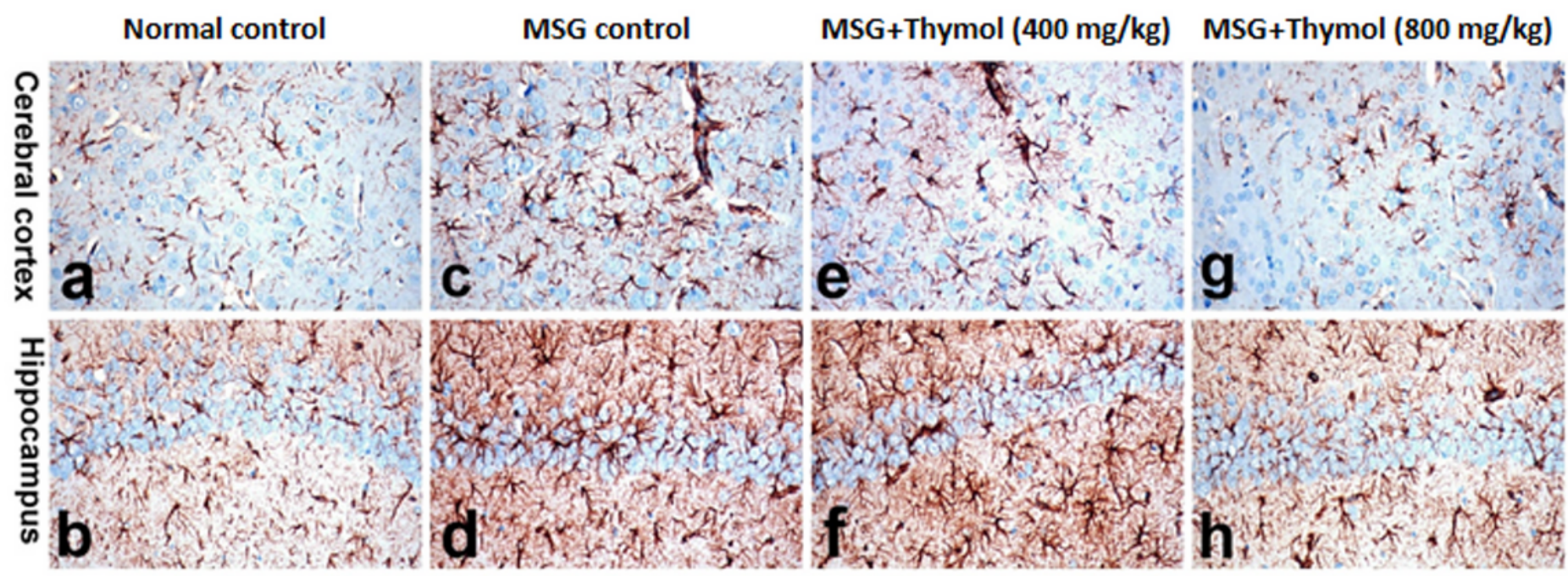

\section{Figure 5}

Immunohistochemical analysis of GFAP expression in cerebral cortex and hippocampus Brain tissues, immunohistochemically stained with GFAP, of $(a, b)$ normal rats showing few weakly stained astrocytes with small cell bodies and short cytoplasmic processes in the cerebral cortex (a) and hippocampus (b); $(c, d)$ MSG-treated rats showing increased GFAP+ astrocytes with large hypertrophied cell bodies and thicker as well as longer cytoplasmic processes in the cerebral cortex (c) and hippocampus (d); (e,f) MSGThymol $(400 \mathrm{mg} / \mathrm{kg})$-treated rats showing few GFAP+ astrocytes with hypertrophied cell bodies in the cerebral cortex (e) and much hypertrophied GFAP+ astrocytes in the hippocampus (f); $(g, h)$ MSG-Thymol $(800 \mathrm{mg} / \mathrm{kg})$-treated rats showing a decreased percentage of GFAP+ astrocytes in the cerebral cortex (g) and hippocampus (h). (GFAP immunohistochemical staining, 40X).

\section{Supplementary Files}

This is a list of supplementary files associated with this preprint. Click to download.

- Graphicalabstract.png 